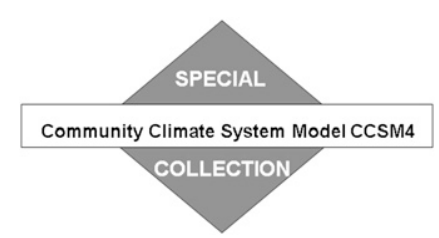

\title{
Will There Be a Significant Change to El Niño in the Twenty-First Century?
}

\author{
SAMANTHA STEVENSON AND BAYLOR FOX-KEMPER \\ Department of Atmospheric and Oceanic Sciences, University of Colorado, Boulder, Colorado \\ Markus Jochum, Richard Neale, Clara Deser, and Gerald Meehl \\ National Center for Atmospheric Research, Boulder, Colorado
}

(Manuscript received 10 May 2011, in final form 22 August 2011)

\begin{abstract}
The El Niño-Southern Oscillation (ENSO) response to anthropogenic climate change is assessed in the following $1^{\circ}$ nominal resolution Community Climate System Model, version 4 (CCSM4) Coupled Model Intercomparison Project phase 5 (CMIP5) simulations: twentieth-century ensemble, preindustrial control, twenty-first-century projections, and stabilized 2100-2300 "extension runs." ENSO variability weakens slightly with $\mathrm{CO}_{2}$; however, various significance tests reveal that changes are insignificant at all but the highest $\mathrm{CO}_{2}$ levels. Comparison with the 1850 control simulation suggests that ENSO changes may become significant on centennial time scales; the lack of signal in the twentieth- versus twenty-first-century ensembles is due to their limited duration. Changes to the mean state are consistent with previous studies: a weakening of the subtropical wind stress curl, an eastward shift of the tropical convective cells, a reduction in the zonal SST gradient, and an increase in vertical thermal stratification take place as $\mathrm{CO}_{2}$ increases. The extratropical thermocline deepens throughout the twenty-first century, with the tropical thermocline changing slowly in response. The adjustment time scale is set by the relevant ocean dynamics, and the delay in its effect on ENSO variability is not diminished by increasing ensemble size. The CCSM4 results imply that twenty-first-century simulations may simply be too short for identification of significant tropical variability response to climate change. An examination of atmospheric teleconnections, in contrast, shows that the remote influences of ENSO do respond rapidly to climate change in some regions, particularly during boreal winter. This suggests that changes to ENSO impacts may take place well before changes to oceanic tropical variability itself become significant.
\end{abstract}

\section{Introduction}

Much effort has been expended on understanding the potential future behavior of the El Niño-Southern Oscillation (ENSO) (Collins et al. 2010; Meehl et al. 2006; Vecchi and Wittenberg 2010; Merryfield 2006). But an often overlooked question underlying the entire debate is the following: what do we really mean by an ENSO "response" to climate change, and when do we expect it to occur? From the perspective of resource management and human impacts, the relevant time horizon is roughly the next 10-50 years (Rajagopalan et al. 2009; Dai et al. 1998; Dettinger et al. 2000; Seager 2007). However, impacts vary with the characteristics of individual

Corresponding author address: Samantha Stevenson, CIRES, 216 UCB, Boulder, CO 80303.

E-mail: samantha.stevenson@colorado.edu
El Niño-La Niña events (McPhaden 1999; Wang and An 2001; Lengaigne and Vecchi 2009; Jin et al. 2003). Even the past few decades show wide variations from event to event, which has prompted some authors to wonder whether ENSO can truly be considered an oscillation, rather than a series of feedback-amplified stochastic anomalies (Thompson and Battisti 2001; Gebbie et al. 2007; Jin et al. 2006).

Approaching the problem from a different direction, there have been numerous studies of ENSO-relevant dynamics that are likely to be affected by global warming (Bony and Dufresne 2005; Liu and Philander 1995; McPhaden and Zhang 2002; Sun 2003). It is possible that external forcing might lead to a change in the types of El Niño-La Niña events that could be expected in the future, and much attention has been paid recently to potential "switches" between modes having centers of action in the eastern and central Pacific (Kao and Yu 2009; 
Yeh et al. 2009). And indeed physical changes to the tropical Pacific, such as alterations of heat content or the structure of the wind stress curl, must necessarily impact ENSO and the tropical heat budget-eventually. But understanding how and when that impact might be realized is not often discussed in the context of coupled model results. This paper will show that it may not be possible to provide a definite answer that is relevant on the societal time horizon.

It has been previously established (Wittenberg 2009; Stevenson et al. 2010) that averaging over several hundred years of model output is required to obtain stable ENSO statistics, under equilibrated background conditions. Over shorter intervals, changes due to natural decadal variability may be substantial, with variance changing by a factor of 2 or more (Wittenberg 2009; Stevenson et al. 2011, manuscript submitted to J. Climate). Here, wavelet probability analysis (WPA; Stevenson et al. 2010) is used to help address the question of statistical reliability. By comparing variability within a wavelet power time series to internal variability in a specified reference (i.e., observations, or a red-white-noise distribution), the significance of spectral variations can be measured in the context of expected decadal changes. Unlike previous climate change studies, WPA allows all members of an ensemble to be considered simultaneously, so that the effects of intrinsic multidecadal ENSO variations can be averaged out as they would be in a longer simulation. However, all of the ensemble members experience the same rapid radiative forcing changes, which are followed by a delay in adjustment of the tropical thermocline. The time scale of these tropical thermocline changes cannot be shortened by increasing the ensemble size.

In state-of-the-art general circulation models (GCMs), the link between ENSO and changes to the mean state of the atmosphere and ocean is unclear (Guilyardi et al. 2009; Collins et al. 2010), possibly due to ENSO's sensitivity to the balance between different feedbacks (Philip and van Oldenborgh 2006, 2010; Guilyardi 2006). Worryingly, even the models that most closely resemble observations do not respond more similarly to one another than does the full Coupled Model Intercomparison Project phase 3 (CMIP3) ensemble (Collins et al. 2010). As a result, two separate but inextricably linked questions arise: what are the main dynamical controls on ENSO amplitude in future climates? And perhaps even more importantly, when can a change in ENSO amplitude be distinguished from natural variability? This study is intended to provide a look at the climate change-ENSO link from a statistical perspective, from which the reliability and relevance of dynamical changes can be understood. Here, the new version of the National Center for Atmospheric Research (NCAR) Community Climate System Model (CCSM4; Gent et al. 2011; this issue), with its improved representation of twentieth century tropical variability (Deser et al. 2012), provides a case study for the ENSO response to climate change.

\section{Model description}

In the atmosphere component of CCSM4, the Community Atmosphere Model version 4 (CAM4; Neale et al. 2011), there have been a number of changes to the dynamics and moist physics. The finite-volume dynamical core (Lin and Rood 1996; Lin 2004) replaces the spectral Eulerian core as the default dynamical core in CAM4. The deep convection scheme has two major modifications: the calculation of convective available potential energy (CAPE) is now based on a dilute-entraining parcel (Neale et al. 2011), and the subgrid-scale vertical transport of momentum by deep convection is included according to Richter and Rasch (2008). Minor modifications are also made to the calculation of cloud fraction in very dry and cold conditions (Vavrus and Waliser 2008).

The convection scheme changes provide significant improvements to the mean atmospheric climate in CAM4 (Neale et al. 2011), and improvements are even larger when CAM4 is coupled within CCSM4 (Gent et al. 2011). More striking are the improvements to transient climate variability within the tropics, related to higher-frequency convectively forced and dynamically coupled variability. Strong precipitation events are more frequent, the precipitation diurnal cycle is more accurate, and the representation of the Madden-Julian oscillation (MJO) (Subramanian et al. 2011) and ENSO (Deser et al. 2012) is improved.

Numerous aspects of the CCSM4 ocean model have improved as well. The full description of the changes and their impacts are detailed in Gent et al. (2011); here, only the changes that proved important for the fidelity of the equatorial Pacific are listed. The horizontal resolution of the ocean model remained unchanged $\left(1^{\circ}\right)$ over the last 5 years but now includes a meridional refinement to $0.25^{\circ}$ at the equator. A significant reduction in viscosity, however, led to a sharpening of the equatorial currents and a realistic representation of tropical instability waves (Jochum et al. 2008). The latter is responsible for removing the cool bias in the equatorial cold tongue.

Below the surface in CCSM3, the maximum equatorial temperature biases at $110^{\circ} \mathrm{W}$ reached $2.5^{\circ} \mathrm{C}$, and they were accompanied by an equatorial undercurrent (EUC) with an overly deep core (Large and Danabasoglu 2006). Compared to the in situ observations from the Tropical Atmosphere Ocean (TAO) array, the CCSM4 hindcast now produces a more realistic temperature, with 
TABLE 1. Simulations used in this study. For transient simulations, the $\mathrm{CO}_{2}$ value quoted is the approximate value at the end of the simulation period.

\begin{tabular}{lrcrl}
\hline \multicolumn{1}{c}{ Simulation } & $\begin{array}{c}\text { Length } \\
(\mathrm{yr})\end{array}$ & $\begin{array}{c}\text { Ensemble } \\
\text { size }\end{array}$ & $\begin{array}{c}\mathrm{CO}_{2} \\
(\mathrm{ppm})\end{array}$ & $\begin{array}{c}\text { Stable/ } \\
\text { transient }\end{array}$ \\
\hline 1850 control (PI) & 1300 & 1 & 250 & Stable \\
Twentieth century & 156 & 6 & 350 & Transient \\
RCP2.6 & 95 & 5 & 450 & Transient \\
RCP4.5 & 95 & 5 & 550 & Transient \\
RCP4.5 extension & 200 & 1 & 550 & Stable \\
RCP8.5 & 95 & 1 & 1300 & Transient \\
\hline
\end{tabular}

a maximum temperature bias of $1.0^{\circ} \mathrm{C}$ at $110^{\circ} \mathrm{W}$ at $100-\mathrm{m}$ depth. Three main changes to the ocean accounted for this improvement, and all three contributed about equally to the sharpening of the thermocline and the lifting of the EUC core. The first was the inclusion of a stratificationdependent isopycnal and thickness diffusion (Danabasoglu and Marshall 2007); the second was an increase of the vertical resolution from 40 to 60 layers (S. Yeager 2008, personal communication); and the third was a reduction of background diapycnal diffusivity from $0.1 \mathrm{~cm}^{2} \mathrm{~s}^{-1}$ to the observed $0.01 \mathrm{~cm}^{2} \mathrm{~s}^{-1}$ (Jochum 2009). The new mixed layer eddy restratification parameterization is based on geostrophic eddies, so it is limited near the equator. However, the parameterization nonetheless affects the subtropical cell circulation (Fox-Kemper et al. 2011, Fig. 7).

Analysis here focuses on the ensemble simulations carried out for the CMIP5; a summary of all simulations used in this study is provided in Table 1. Ensemble simulations have been carried out for the twentieth century, as well as four different projections of the twenty first. The so-called radiative concentration pathways (RCPs) provide a profile of radiative forcing, derived using four different socioeconomic models (Moss et al. 2010). Hereafter, the RCP ensembles are referred to by their top-of-atmosphere radiative imbalances (globally averaged, $\mathrm{W} \mathrm{m}^{-2}$ ): $\mathrm{RCP} 2.6, \mathrm{RCP} 4.5, \mathrm{RCP} 6.0$, and RCP8.5. The RCP6.0 simulations were not complete at the time of writing, so they are not included in the subsequent analysis.

To understand differences between the stable and transient mean-state simulations, output from two stable control simulations is used. The first is the 1300 -yr preindustrial control (Gent et al. 2011) carried out under $1850 \mathrm{AD} \mathrm{CO}_{2}$ concentrations. The next is the so-called extension run for RCP4.5, designed to describe the climate from 2100-2300 after $\mathrm{CO}_{2}$ concentrations have stabilized. Extension runs are planned for all RCPs, but as of yet the others have not yet been completed. Note that the extension runs are themselves not sufficiently long to provide robust ENSO statistics; a detailed examination of changes to ENSO in a stabilized mean climate must wait for future work [although Stevenson et al. (2011, manuscript submitted to J. Climate) provides a look at this question using a slightly older version of the CCSM at coarser resolution].

\section{Statistical reliability}

The fundamental question addressed in this paper is how does ENSO respond to climate change? Here, we define an ENSO amplitude "response" as a statistically significant difference in the variability of Niño-3 SST $\left(5^{\circ} \mathrm{N}-5^{\circ} \mathrm{S}, 90^{\circ}-150^{\circ} \mathrm{W}\right)$; our results do not fundamentally change if Niño-3.4 $\left(5^{\circ} \mathrm{N}-5^{\circ} \mathrm{S}, 80^{\circ}-170^{\circ} \mathrm{W}\right)$ or Niño-4 $\left(5^{\circ} \mathrm{N}-5^{\circ} \mathrm{S}, 160^{\circ} \mathrm{E}-150^{\circ} \mathrm{W}\right)$ is used.

Wavelet spectra for both Niño-3 and Niño-4 SST are shown for all ensembles in Figs. 1b,c. In both indices, the twentieth century and RCP ensembles overlap substantially, despite a slight tendency toward weakening at higher $\mathrm{CO}_{2}$. The shape of the spectral envelope also appears to change somewhat, with the RCP ensembles having a weaker annual cycle than the twentieth century. At periods longer than 7 years, nearly no change is seen in spectral power between any ensembles. To contrast with the forced ensembles, spectra of consecutive 100-yr subsamples taken from the stabilized 1850-1990 controls and the RCP 4.5 extension are shown in Fig. 1a. Once again, there is a large degree of overlap, though the range of variability is noticeably smaller in the shorter RCP4.5 extension run. But how significant are the changes between ensembles?

The statistics of ENSO very rarely follow well-defined probability distribution functions (PDFs), making parametric tests of significance such as the $T, F$, or $\chi^{2}$ tests inappropriate (Montgomery and Runger 2007). Therefore, several nonparametric test results are shown in Fig. 2. The first is a bootstrap confidence interval on the bandpassed 2-7-yr Niño-3 SST variance. Intraensemble changes are assessed using the $90 \%$ confidence interval on the 30-yr variance (Fig. 2a) - confidence intervals overlap between all ensembles. By this measure, all ensembles are statistically indistinguishable. Note particularly the large spread in variance observed during the control simulations-these encompass all of the forced ensembles' $90 \%$ confidence intervals, illustrating the large range of natural ENSO variability. Clearly, 30-yr subsamples are too short to distinguish between climate projections.

The overall Niño-3 variance appears to weaken with increasing $\mathrm{CO}_{2}$, but $90 \%$ confidence intervals on the variance over the full simulation period overlap with the twentieth century for all RCP ensembles except RCP8.5 (Fig. 2a, green lines). Taken by itself, this would indicate that climate change leads to significant ENSO weakening only for very high $\mathrm{CO}_{2}$ emissions pathways. But the 


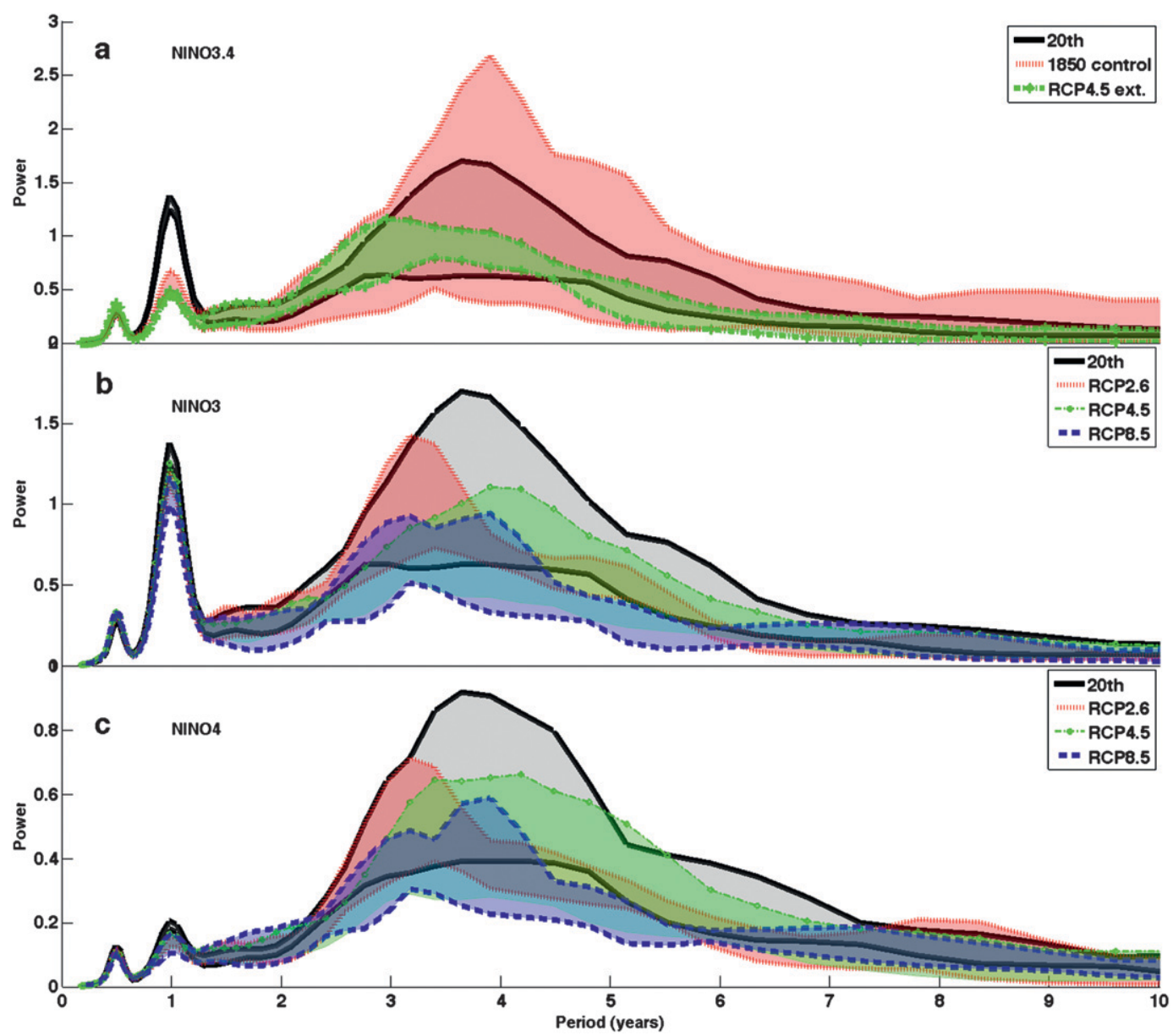

FIG. 1. Spectral "envelopes" for each CCSM4 ensemble, calculated using a Morlet wavelet transform of the SST time series. (a) Niño-3.4 SST for the twentieth-century ensemble, preindustrial (1850) control, and the RCP4.5 extension. (b) Niño-3 SST for the twentieth- and twenty-first-century ensembles. (c) As in (b), but for Niño-4 SST. Envelopes for the forced ensembles are calculated by finding the maximum and minimum at each wavelet scale from spectra of each ensemble member. Envelopes for the 1850 control and RCP4.5 extension are calculated from spectra of $100-\mathrm{yr}$ subintervals of those simulations.

results from the stable control simulations indicate that the situation may be more complex. These simulations are long enough to provide reasonably stable ENSO statistics (Stevenson et al. 2010), which is reflected in their much smaller $90 \%$ confidence intervals. When 100 -yr subsamples are used to calculate the bootstrap confidence interval (Fig. 2a, red lines), Niño-3 variances are still statistically identical, but the error bars have shrunk considerably. Then for the 1850 control, even longer subsamples may be used (Fig. 2a, yellow lines); 300 years is sufficient to identify a significant difference between simulations, as was the case in Stevenson et al. (2011, manuscript submitted to J. Climate). In other words, significant ENSO changes can only be observed after the climate has stabilized, by averaging a sufficient number of model years (see also section 4). The twentieth century does not differ from either future or past ENSO variability, and only when $\mathrm{CO}_{2}$ is held constant for several centuries can ENSO differences be reliably detected.

Another common metric for statistical significance, the Kolmogorov-Smirnov (K-S) test on Niño-3 SST, is used to examine changes to the distribution of $2-7-\mathrm{yr}$ bandpass-filtered Niño-3 SST. The K-S test shows that the probability distribution functions (PDFs) of Niño-3 SST (as well as SST anomaly; not shown) are significantly different between every possible combination of ensembles, indicating that a shift in the statistics of El Niño-La Niña events occurs, despite the lack of a significant overall change in variance with $\mathrm{CO}_{2}$. Natural variability among ensembles also leads to significant changes in the Niño-3 SST PDFs as measured by the K-S test, even though these distributions are by definition generated from the same physical processes. 

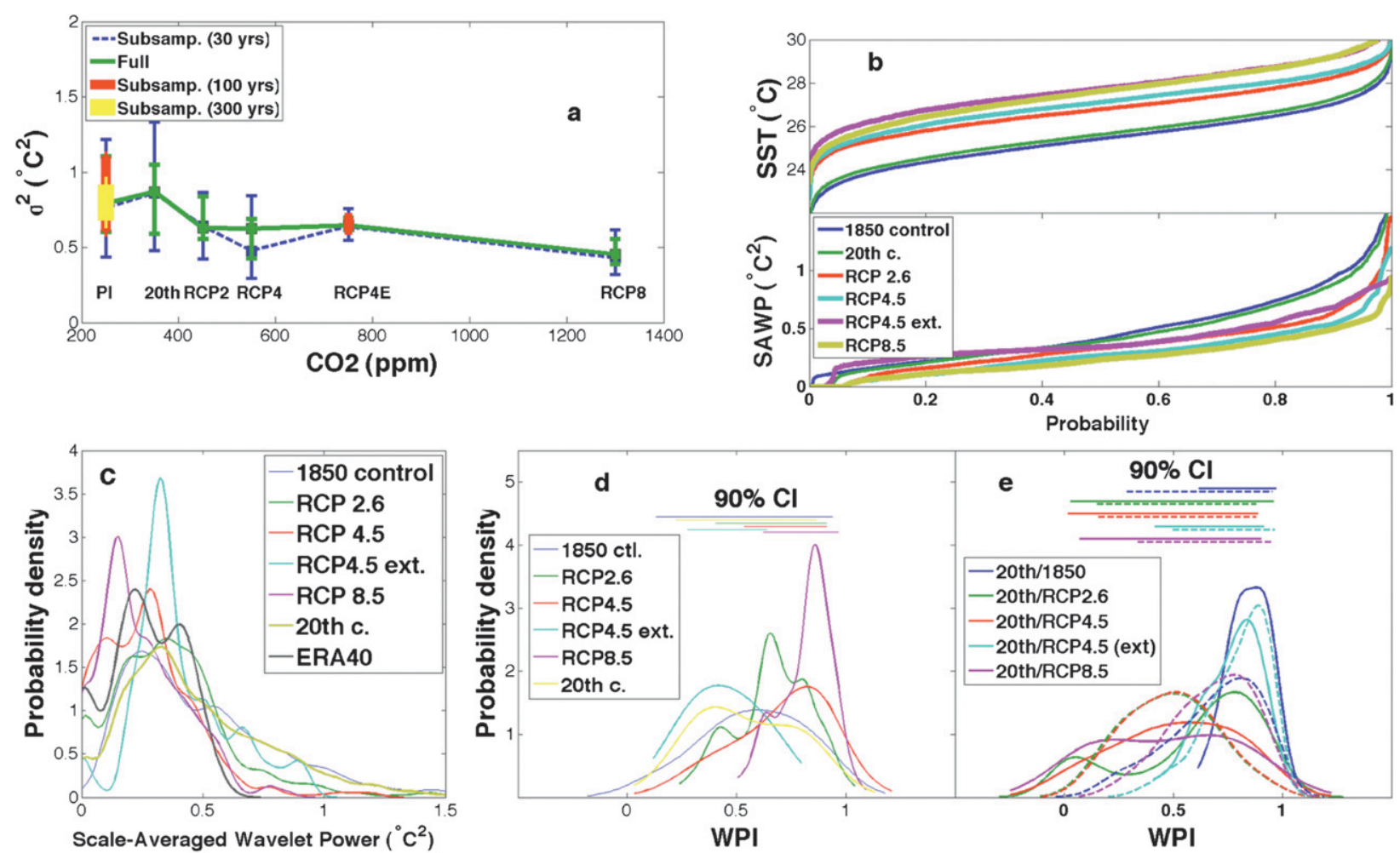

FIG. 2. Diagnostics used by four different statistical tests to detect changes to ENSO variability between ensembles. (a) Bandpassed (2-7-yr) Niño-3 SST variance with $90 \%$ bootstrap confidence intervals, calculated both for the full time span of each ensemble and for 30-yr subintervals. (b) Cumulative distribution functions for (top) Niño-3.4 SST and (bottom) the scale-averaged wavelet power between 2 and 7 years. (c) Probability density function for mean wavelet power. (d),(e) WPI distributions used in hypothesis testing procedure. (d) Distributions calculated relative to the 1850 control, and (e) distributions calculated relative to an AR(1) fit. Solid lines represent the $90 \%$ confidence interval for the WPI distributions generated from model subintervals, dashed lines the same for the AR(1) fits to each model. All WPI distributions use 30-yr subintervals.

The $\mathrm{K}-\mathrm{S}$ test is also applied to the scale-averaged wavelet power (SAWP; Torrence and Compo 1998) between 2-7-yr periods, which is defined according to

$$
\mathrm{SAWP}=\frac{\delta j \delta t}{C_{\delta}} \sum_{j=j_{1}}^{j_{2}} \frac{\left|W_{n}\left(S_{j}\right)\right|^{2}}{S_{j}},
$$

where $W_{n}(s)$ is the wavelet spectrum, $\delta j$ and $\delta t$ are the discrete steps in scale and time, and $C_{\delta}$ is a constant appropriate to the wavelet function being used (for Morlet, $C_{\delta}=0.776$; Torrence and Compo 1998). As with Niño-3 SST, the K-S test shows that all of the SAWP distributions differ. We have here a situation where the distribution shapes of SST and SAWP differ, yet the total variance in the time series is the same. This seems contradictory in some sense, since the total amount of variability is constant yet the $\mathrm{K}-\mathrm{S}$ test results would suggest that there is a statistical difference. A less sensitive test is therefore necessary to determine when a spectral shift is truly distinct from natural variability.
The newly developed wavelet probability analysis toolkit of Stevenson et al. (2010) provides a more appropriate comparison. This test compares the joint probability between subintervals of a wavelet spectrum (either at a given period or averaged over a range of wavelet scales), which is a measure of the degree to which the overall behavior of the oscillation changes with time. The advantage of this approach over the $\mathrm{K}-\mathrm{S}$ test is that it does not require that the two distributions being compared be equal, only that they cover similar ranges of spectral power. The test statistic is the distribution of wavelet probability index (WPI) the joint probability between subintervals. WPA has proven useful at identifying known offsets in model ENSO spectra from observations, in the CCSM3.5 and other coupled models (Stevenson et al. 2010, 2011, manuscript submitted to J. Climate).

Example PDFs of SAWP are shown in Fig. 2c, each generated using the full set of members for each ensemble. During the WPI calculation, the PDFs of SAWP for subsamples of individual ensemble members are 
calculated, and the overlap between each pair of PDFs forms a single WPI value. Distributions of the WPI values are then used in the testing procedure. In all cases, the ensembles are considered as a group-thus the six twentieth-century simulations are compared with the five RCP4.5 simulations, etc. This approach creates the largest possible sample size. ${ }^{1}$

A qualitative sense of the behavior of each ensemble may be gained from Fig. 2c: substantial overlap is seen between the Niño-3 SAWP PDFs, but generally speaking the lower- $\mathrm{CO}_{2}$ simulations show a larger high-power "tail" (or conversely, fewer strong events occur at higher $\mathrm{CO}_{2}$ ). This is simply another way of visualizing the spectral overlap seen in the envelopes of Fig. 1.

WPI distributions generated using the CCSM4 ensembles are shown in Figs. 2d,e. Two different null hypotheses are adopted for the test; the first is the simple null hypothesis used by Stevenson et al. (2010) that internal variability within a long "reference" time series can lead to the same range of WPI values observed when comparing subsets of the two time series of interest (i.e., the twentieth versus twenty-first centuries). This is measured using the 1850 control as the reference; the WPI distributions generated from the overlap between $30-\mathrm{yr}$ segments of the 1850 control and the twentieth- and twenty-first-century ensembles, respectively, are tested against one another. Figure $2 \mathrm{~d}$ shows the WPI distributions with the corresponding $90 \%$ confidence interval (lines above the WPI distributions) - it is clear that all of the confidence intervals overlap. Note in particular how much the WPI confidence intervals for the RCP4.5 and its extension differ-even though these two runs reach the same level of top-of-atmosphere radiative imbalance, their confidence intervals barely overlap, making a stark contrast with the large overlap between the various twentieth-century ensembles.

The second WPA null hypothesis is that low-frequency noise could create the observed degree of spectral overlap. The WPI distributions derived from the CCSM are now compared to those generated from a first-order autoregressive $[\mathrm{AR}(1)]$ red-noise distribution, where the lag- 1 autocorrelation is derived from each of the two input time series. WPI distributions are shown in Fig. 2e; now a significant difference is indicated by a lack of overlap between the $90 \%$ confidence interval on WPI from the AR(1) fit (dashed line) and the corresponding ensemble (solid line of the same color). Comparing the color-coordinated line pairs at the top of Fig. 2e, we see

\footnotetext{
${ }^{1}$ Note that the first 10 years of each simulation are excluded to minimize effects from mutual information due to common initial conditions.
}

that once again they overlap; there is no significant change in any of the ensemble combinations. Despite the significance of changes to the shape of the SST and wavelet power PDFs in Fig. 2c, these changes cannot be distinguished from those one might expect due to the "noisiness" of natural variability.

An interesting note is that the ENSO response to increased $\mathrm{CO}_{2}$ is entirely different in the CCSM4 and the CCSM3.5 equilibrated simulations [this study and Stevenson et al. (2011, manuscript submitted to J. Climate), respectively]. In the CCSM4-forced ensembles, ENSO seems to weaken slightly with $\mathrm{CO}_{2}$, but the stable simulations of Stevenson et al. (2011, manuscript submitted to J. Climate) show an increase in ENSO amplitude. Intuitively, one might expect that a given climate model would exhibit a certain pattern of ENSO sensitivity to $\mathrm{CO}_{2}$, but it appears that even small changes to model physics are sufficient to lead to dramatic changes in the simulated ENSO response to climate change (Jochum et al. 2010). Model resolution may be responsible; westerly wind bursts, for example, are entirely absent in the coarse-resolution CCSM3.5, and changes in stochastic forcing might potentially drive shifts in the ENSO sensitivity (Jochum et al. 2009). However, a detailed examination is beyond the scope of this paper; a discussion can be found in Stevenson et al. (2011, manuscript submitted to J. Climate).

\section{Changes to mean circulation}

Given that overall ENSO response does not seem to be significant for the forced ensembles, we next look for changes to the atmosphere-ocean mean state. Basic-state variables are closely linked to ENSO dynamics in all theoretical models of the oscillation (e.g., Suarez and Schopf 1988; Jin 1997; Weisberg and Wang 1997; Battisti and Hirst 1989, and many more-see Neelin et al. 1992; Wang and Picaut 2004 for reviews) and relationships with atmosphere-ocean mean-state variables are often used to explain various aspects of ENSO dynamics. For example, shifts between surface and thermocline-driven ENSO modes may be related to zonal wind stress as well as the depth and stratification of the mean thermocline (Fedorov and Philander 2001), while the meridional extent of the subtropical wind stress is related to the ENSO period in coupled climate models (Capotondi et al. 2006). Examples of the mean state-ENSO interaction are too numerous to completely describe here, although the subject is of considerable interest for ENSO studies using coupled GCMs (Guilyardi 2006). Unfortunately, given the lack of significance in Niño index spectra seen in section 3, quantifying the importance of these mechanisms in the CCSM4 is not physically meaningful. However, it is still 

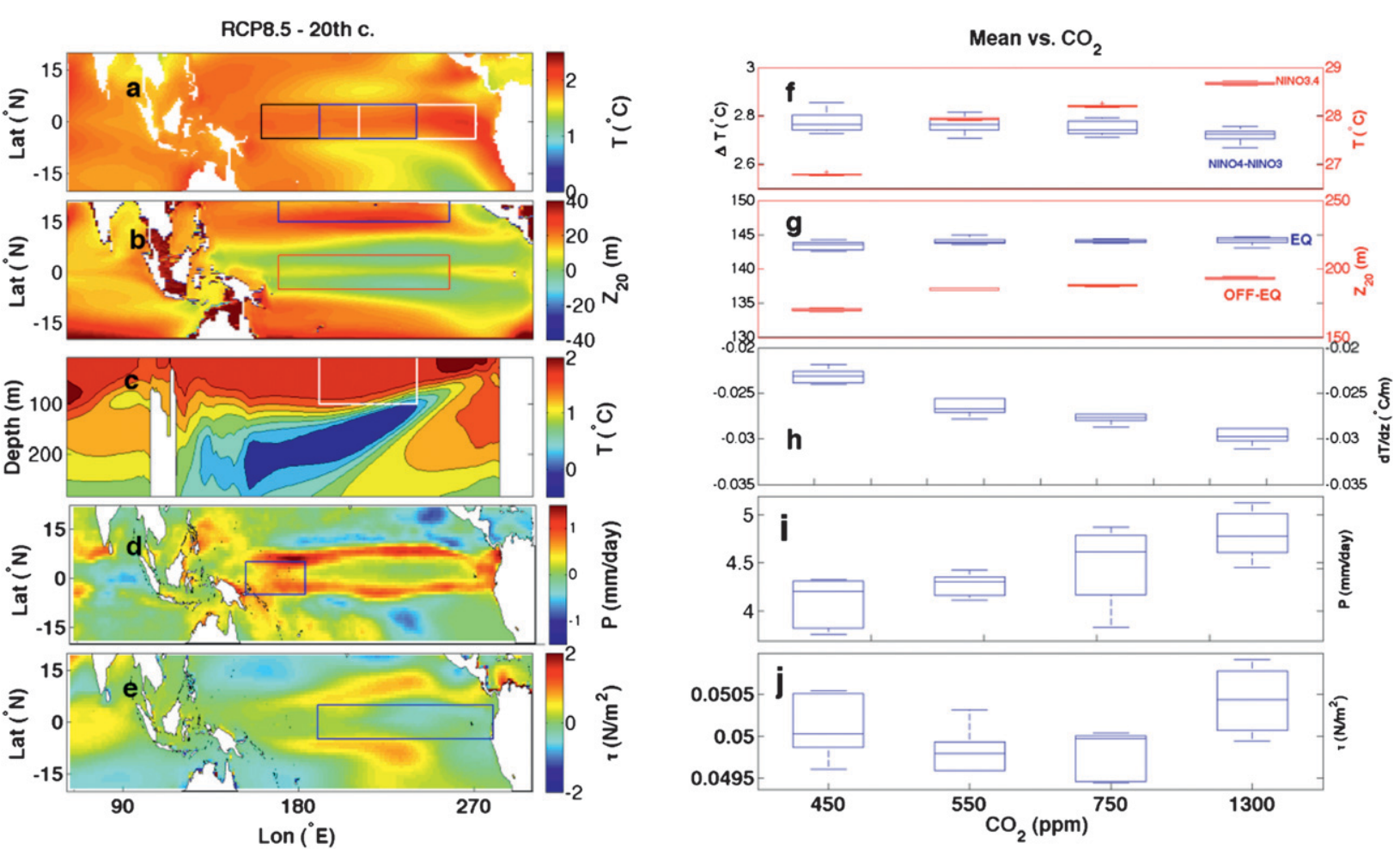

FIG. 3. Summary of changes to the atmosphere-ocean mean state between CCSM4 ensembles. (left) Ensemble-mean pattern of changes between RCP8.5 and the twentieth century with rectangular boxes indicating averaging regions. (right) Distribution of regionally averaged diagnostics for each ensemble, corresponding to the quantity on the left, as a function of $\mathrm{CO}_{2}$ stabilization level. (a) SST $\left({ }^{\circ} \mathrm{C}\right)$; (b) thermocline depth $Z_{20}$; (c) Vertical temperature profile $\left({ }^{\circ} \mathrm{C}\right)$; (d) wind stress magnitude $\left(\mathrm{N} \mathrm{m}^{-2}\right)$; (e) precipitation $\left(\mathrm{mm}^{-1}{ }^{-1}\right)$. Note that (h) the vertical temperature derivative $d T / d z$ rather than the mean value of $T(z)$ is shown; here, $z$ is positive downward, and $d T / d z$ has units of ${ }^{\circ} \mathrm{C} \mathrm{m}^{-1}$. (right) The horizontal lines inside the boxes indicate the ensemble median, the extent of the boxes the distance between the 25 th and 75 th percentiles, and the whiskers the 2.5 th and 97.5 th percentiles. Where present, + symbols indicate outliers. All box averages on the right-hand side show the averages inside the boxes drawn on the left-hand panels: with the exception of (h), which instead shows the vertical derivative of temperature averaged inside the box in (c).

important to note the direction of the CCSM4 meanstate response to climate change to provide a benchmark for use in future multimodel comparison studies.

Figure 3 shows the changes to the atmosphere-ocean mean state in five different variables: SST, thermocline depth $Z_{20}$, vertical temperature profile, precipitation, and wind stress magnitude. In each row, the left-hand panel shows the ensemble-mean difference between RCP8.5 and the twentieth century as a map over the tropical Pacific (or in the case of the vertical temperature profile, as a cross section over $5^{\circ} \mathrm{S}-5^{\circ} \mathrm{N}$; Fig. 3c). The corresponding right-hand panel shows the distribution of the ensemble member means for the appropriate variable, averaged over the box pictured on the map at left. ${ }^{2}$ This allows changes with $\mathrm{CO}_{2}$ in regions of interest to be easily visualized.

\footnotetext{
${ }^{2}$ Panel (h) is an exception; this shows the vertical temperature derivative averaged over the box in panel (c), rather than the mean temperature.
}

Changes to SST are shown in Figs. 3a,f. Warming is most pronounced along the equator, consistent with predictions of enhanced meridional SST gradients from previous analyses (Gastineau et al. 2009; Liu et al. 2005; Xie et al. 2010; Zhang et al. 2009). Stronger warming is seen in response to $\mathrm{CO}_{2}$ increases in the eastern Pacific than in the west, which has been seen in multimodel experiments (Collins et al. 2010) as well as stabilized climate experiments with the CCSM3.5 (Stevenson et al. 2011, manuscript submitted to J. Climate).

Changes to the ocean stratification are known to affect ENSO dynamics (Jochum et al. 2010; Liu and Philander 1995; Yeh et al. 2006), and previous authors have predicted that the stratification should increase in response to climate change (Timmermann et al. 1999; Merryfield 2006). Figure $3 \mathrm{c}$ shows the same result, with stronger warming observed above the thermocline than at depth. The increase in stratification may be observed directly in Fig. 3h, where the vertical temperature derivative in the eastern Pacific averaged over the top $100 \mathrm{~m}$ is plotted. 

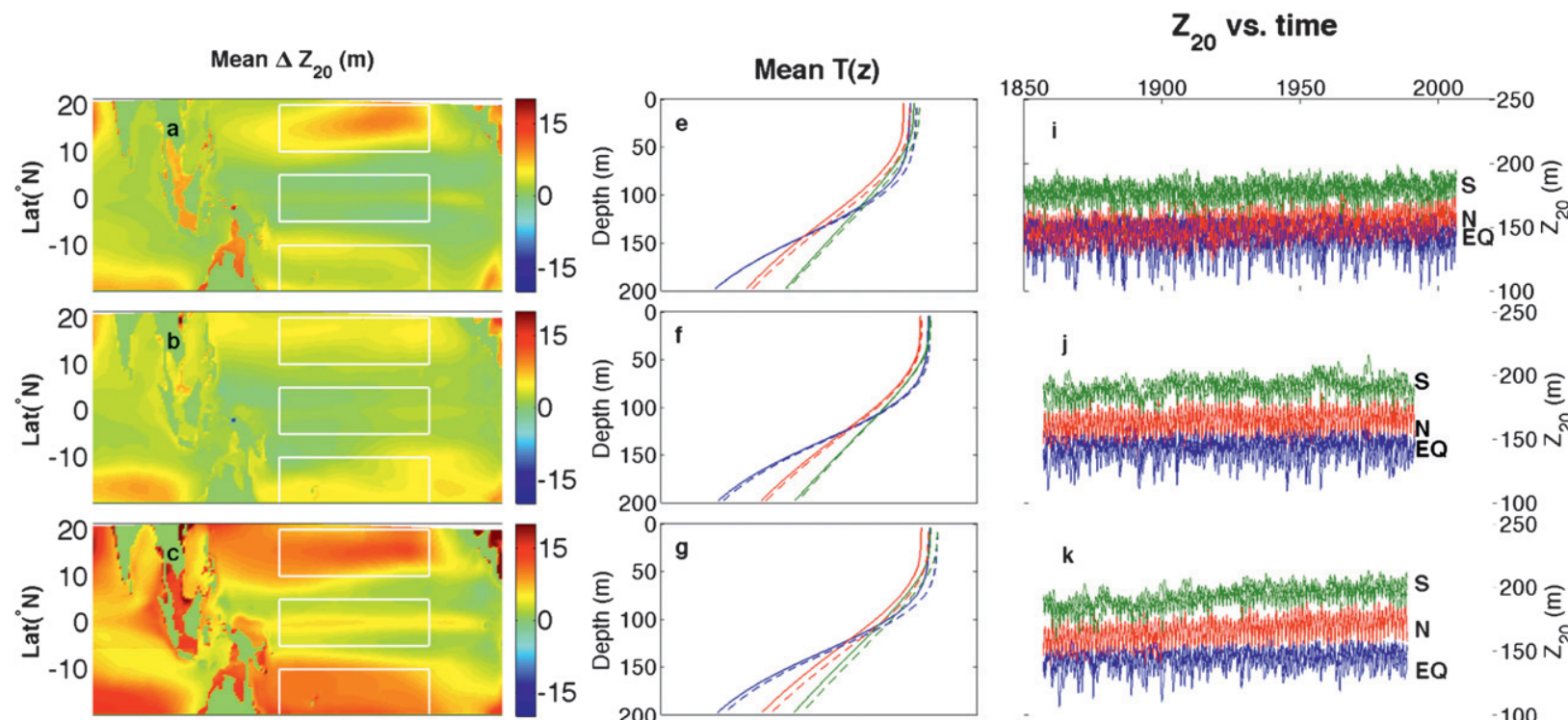

100
-250
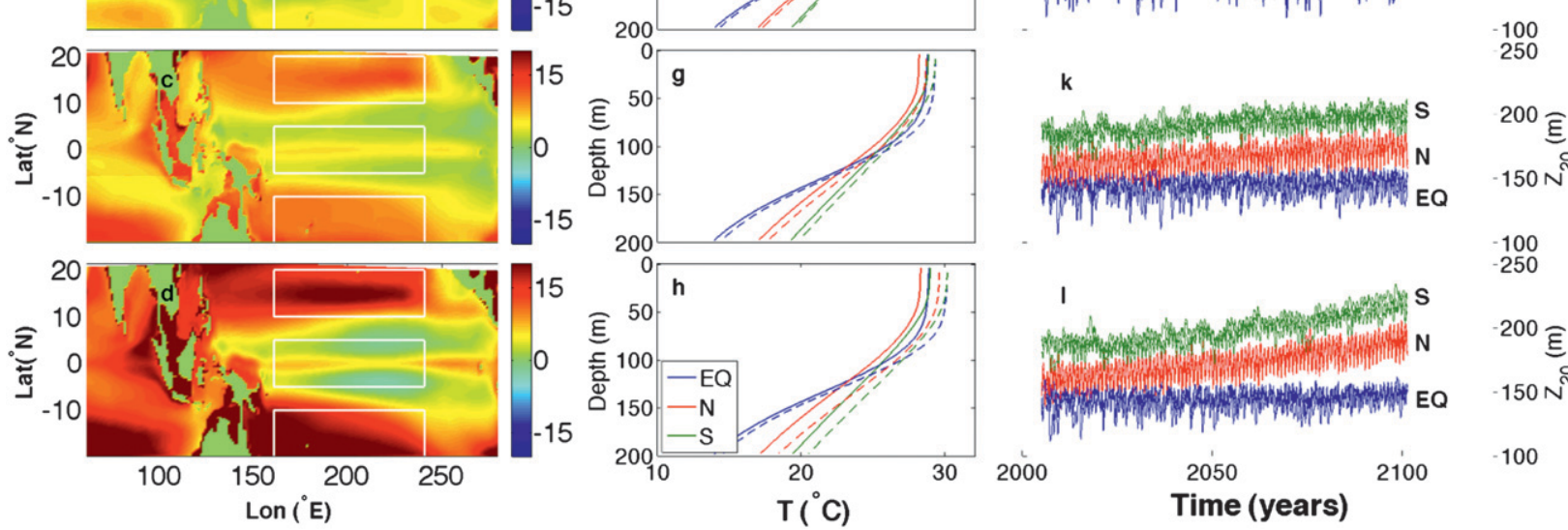

k

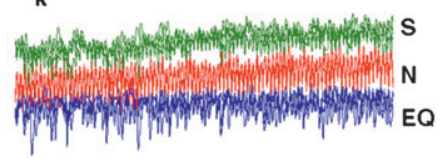

$200 \widehat{\underline{\xi}}$ $150 N^{N}$ $200 \widehat{\underline{\xi}}$ -150 N 100
250 100 -100
-250

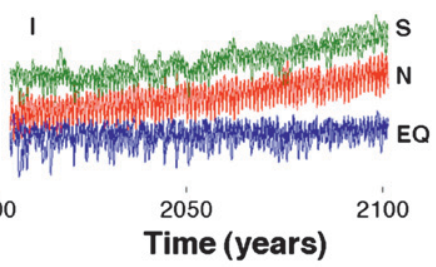
$-200 \widehat{\underline{\xi}}$ $-150 N^{2}$ $-100$

FIG. 4. Trends in thermocline depth (measured as the depth of the $20^{\circ} \mathrm{C}$ isotherm) for the CCSM 4 ensembles. (left) (a)-(d) Difference maps taken between the first and second halves of the run: (2051-2100) - (2005-50) for the RCPs, and (1931-2005) - (1850-1930) for the twentieth century. (middle) (e)-(h) The vertical profiles of temperature averaged over the three boxes pictured at left: equatorial (EQ), northern $(\mathrm{N})$, and southern $(\mathrm{S})$. In these panels, the solid lines show the vertical profiles for the first half of the run and the dashed lines the profiles for the second. (right) (i)-(1) The time series of thermocline depth averaged over the same regions. Rows correspond to the four simulation ensembles: (a),(e),(i) twentieth century, (b),(f),(j) RCP2.6, (c),(g),(k) RCP4.5, and (d),(h),(l) RCP8.5.

Thermocline depth ensemble-mean differences show substantial effects in the extratropics (Figs. 3b,g). Poleward of $10^{\circ}$, all of the RCP ensembles show a pronounced deepening of the thermocline with $\mathrm{CO}_{2}$, which is especially strong in RCP8.5 (Fig. 3g, red boxes). Near the equator, the deepening is minimal, with changes to thermocline depth less than $10 \mathrm{~m}$ (Fig. 3g, blue boxes). Note that the $20^{\circ} \mathrm{C}$ isotherm has been used to define the thermocline, which is not an ideal metric given the large changes to SST expected under global warming. However, test cases calculated using latitudinally varying thermocline definitions show the same results, indicating that the overall dynamics are insensitive to the exact definition used. Additionally, the center panels in Fig. 4 make it clear that extratropical deepening is observed regardless of the threshold temperature used to define the thermocline.

A weakening of the atmospheric overturning circulation is expected in response to climate change (Vecchi and Soden 2007; Held and Soden 2006) due to an imbalance between increases in the evaporative flux and convective precipitation, and signatures of such a weakening are seen in CCSM4. Figures 3d,i show ensemblemean precipitation differences; although the increase is likely not significant because of the substantial overlap between ensembles (Fig. 3i), the ITCZ strengthens somewhat in all RCPs relative to the twentieth century, especially in the southern branch [South Pacific convergence zone (SPCZ); Fig. 3d].

Figures $3 e, j$ show the changes to wind stress magnitude $\tau$; there is some strengthening of $\tau$ at $5^{\circ} \mathrm{N}$ and $\mathrm{S}$ (Fig. 3e), which comes primarily from increased meridional wind stress (not shown). Reductions in $\tau$ are roughly $5 \%-10 \%$ of the twentieth-century trade wind strength along the equator, though again the ranges covered by all ensembles overlap (Fig. 3j). In zonal wind stress (not shown), there is a strong hemispheric asymmetry in the Pacific trade wind shifts. The Northern Hemisphere trades (between $10^{\circ}$ and $20^{\circ} \mathrm{N}$ ) are reduced by 2-3 times as much as their Southern Hemisphere counterparts, possibly due to the higher air-sea contrast created by the larger Northern Hemisphere landmasses. The trade wind asymmetry 
is consistent with the hemispheric asymmetry in overall warming, which has been shown to be 2-3 times stronger in the Northern Hemisphere in CCSM4. From geostrophy, a stronger reduction in the meridional temperature gradient in the Northern Hemisphere will in turn lead to a greater weakening of the trade winds.

A more direct visualization of the ocean stratification changes is provided in the center panels of Fig. 4. This shows the vertical temperature profiles for each simulation, averaged in equatorial and off-equatorial regions during the first and second halves of each simulation period (1850-1930 and 1931-2000 for the twentieth century, 2005-50 and 2051-2100 for the RCPs). Differences between the first and second half of the twentieth century and of RCP2.6 are minimal (Figs. 4e,f), with mean temperature profiles nearly indistinguishable from one another in both the equatorial and off-equatorial regions. At higher $\mathrm{CO}_{2}$, trends within the simulations become more apparent, especially in the extratropics. In RCP4.5, warming of roughly $0.5^{\circ} \mathrm{C}$ is seen in the mixed layer from 2051-2100 relative to $2005-50$ (Fig. $4 \mathrm{~g}$ ); this warming is larger, on the order of $1^{\circ} \mathrm{C}$, in RCP8.5 (Fig. 4h). But most interesting is the warming at depth; offsets of $0.5^{\circ} \mathrm{C}$ are visible down to $200 \mathrm{~m}$ in $\mathrm{RCP} 8.5$, but the equatorial temperature profile shows virtually no subsurface change. The same effect is shown in the maps in Figs. $4 \mathrm{a}-\mathrm{d}-$ the extratropical thermocline depth changes at high $\mathrm{CO}_{2}$ are much larger than the tropical. Likewise, the time series in Figs. 4i-l clearly show that the extratropical thermocline is deepening and that the deepening in the RCPs shows no sign of stopping at year 2100; yet the trend in the tropical thermocline is smaller, consistent with a delayed response in the tropics. Note that the trends in these panels are statistically significant, even when they appear visually quite small in Fig. 4.

Why is it that the change in tropical thermocline depth lags behind that in the subtropics? First of all, the subtropical thermocline is in the region of Ekman convergence, downwelling, and subduction, while Ekman divergence and upwelling affect the tropical thermocline (at least within the cold tongue, where ENSO is most active). Thus, the subtropical thermocline's temperature and volume transport are locally determined, while the tropical thermocline depends both on the local upwelling-mixing and on the density and temperature of water supplied from remote sources. The adjustment of the tropical thermocline to extratropical perturbations is therefore a combination of wave adjustment, advective supply, and diabatic balance (e.g., Cane and Sarachik 1979; Gu and Philander 1997; Boccaletti 2005).

While estimates differ on the delay time scale because forcing of downwelling regions (and consequently the wave and advective pathways) differ substantially among models, most studies arrive at a decadal or multidecadal lag for the tropics after an impulsive extratropical perturbation. The time scale of warming the subtropics by an $O\left(1 \mathrm{~W} \mathrm{~m}^{-2}\right)$ perturbation is long (14 years to warm $100 \mathrm{~m}$ of water by $1 \mathrm{~K}$ ), and the communication time scale is also long (perhaps as long as a decade for the waters making up the EUC; Blanke and Raynaud 1997; Kessler 2006). Finally, as Boccaletti (2005) and Boccaletti et al. (2004) show, the rebalancing of the heat budget of the system as a whole requires adjustment of the equatorial diabatic fluxes and a return of the signal to the original perturbation location via Rossby and Kelvin waves. In all, it is not surprising that the time scale for adjustment of the whole system is comparable to or longer than the length of the RCP simulations. It should be noted that this is a direct consequence of the large-scale ocean dynamics involved and is expected to be a common feature among all coupled models.

\section{ENSO modes and teleconnections}

The large interensemble mean-state changes in section 4 may reasonably be expected to translate into changes to the teleconnections between ENSO and extratropical atmospheric circulation (Alexander et al. 2002; Diaz et al. 2001; Meehl et al. 2006; Xie et al. 2010), as well as the overall modes of variability (Yeh et al. 2009; Capotondi et al. 2006; Deser et al. 2006). Atmospheric teleconnections are known to experience substantial decadal modulation (McCabe and Dettinger 1999; Power et al. 1999, 2006; Trenberth and Hurrell 1994) but may nonetheless be expected to behave differently in future climates (Cane et al. 1997; Diaz et al. 2001). Of course, the large number of ENSO teleconnections identified in the literature makes a comprehensive examination impossible; as such, El Niño and La Niña composite atmospheric maps provide a representative example. It is hoped that this brief overview of teleconnection changes may lead to a more detailed investigation in future studies.

The composite El Niño and La Niña differences in sea level pressure (SLP) and surface air temperature (SAT) are shown during boreal summer and winter [JuneAugust (JJA) and December-February (DJF), respectively; Figs. 5-8]. These fields are chosen for their ability to simply represent the atmospheric teleconnection patterns; SLP anomalies in particular have been shown to be indicative of the upper-air circulation anomalies (Deser et al. 2012). In Figs. 5-8, El Niño and La Niña phases are shown separately to avoid confusion due to possible nonlinear shifts in teleconnection dynamics (i.e., Okumura and Deser 2010). 

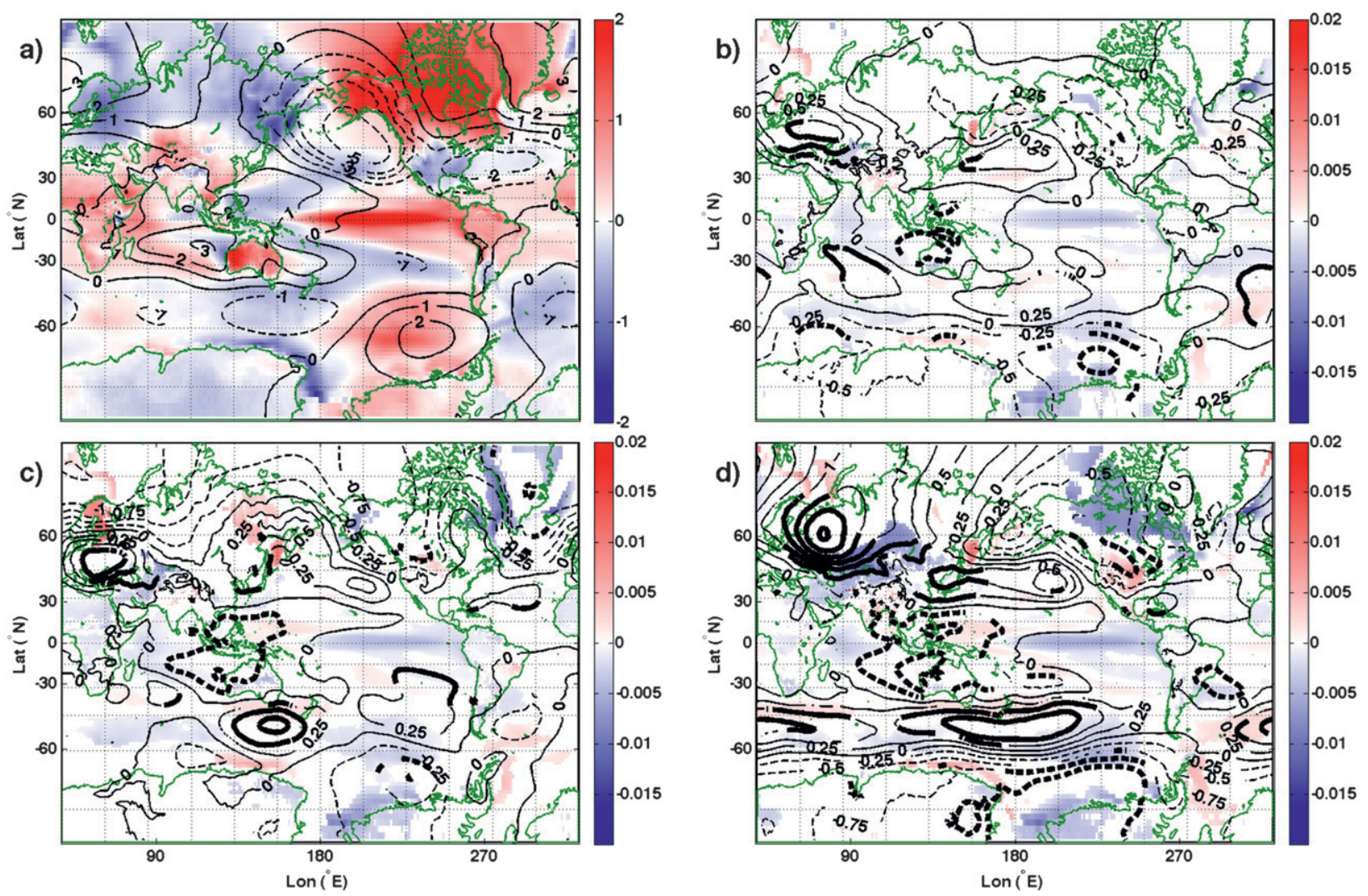

FIG. 5. Composite El Niño DJF anomaly map for the CCSM4 ensembles. In Figs. 5-8, El Niño and La Niña events are defined as years where the deseasonalized DJF Niño-3.4 SST anomaly exceeds \pm 1 standard deviation relative to a linearly detrended time-mean state. (a) Composite for twentieth-century ensemble, (b) RCP2.6-twentieth century, (c) RCP4.5-twentieth century, and (d) RCP8.5-twentieth century are shown. In all panels, surface air temperature $\left({ }^{\circ} \mathrm{C}\right)$ is shown in color and sea level pressure $(\mathrm{hPa})$ is shown in contours (contour interval $0.25 \mathrm{hPa}$ ). Negative anomalies are indicated as blue colors or dashed contours. (b)-(d) SLP anomalies significant at $90 \%$ are indicated by thicker contours, and only the significant surface air temperature values are plotted.

This analysis is similar to the approach of Deser et al. (2006); El Niño and La Niña events are defined as periods where the three-month deseasonalized mean Niño-3.4 SST difference from the mean for the appropriate ensemble member exceeds +1 standard deviation during DJF. Biases due to the differing mean-state trends between ensembles are corrected for by linearly detrending prior to calculating the standard deviation. Any predictability to the changes to teleconnections with $\mathrm{CO}_{2}$ should then show up as a $\mathrm{CO}_{2}$-dependent shift in the composite plots in Figs. 5-8. To ensure that only significant anomalies are examined, the Wilcoxon ranksum test is applied to the set of SAT and SLP anomalies at each grid point, and only SAT anomalies significant above $90 \%$ are shown. Significant SLP anomalies are indicated by thickened contours, but the full SLP anomaly pattern has been retained to provide visual context.

The overall weakening of ENSO in the twenty-firstcentury ensembles is reflected in the smaller equatorial Pacific surface temperature anomalies in the RCPs relative to the twentieth century, which appear as negative (positive) anomalies during El Niño (La Niña). However, ensemble-mean anomalies are very small $\left(\leq 0.1^{\circ} \mathrm{C}\right)$. The change with the largest magnitude occurs during La Niña in DJF (Figs. 6b-d) — a pronounced high pressure anomaly to the south of Alaska forms in the higher- $\mathrm{CO}_{2}$ ensembles. This is essentially a strengthening of the blocking high typically associated with La Niña events, which is accompanied by colder air temperatures over Canada and the northern United States.

High pressure anomalies are observed during El Niño DJF in the Southern Hemisphere subtropics, which become statistically significant in RCP4.5 and RCP8.5. These anomalies are strongest south of Tasmania and are accompanied by negative SLP anomalies over western Australia and Indonesia. SAT and SLP anomalies of opposing sign occur in these regions during La Niña DJF (Figs. 6b-d), which are statistically significant over the Southern Ocean but not over mainland Australia. Taken together, these changes seem to indicate a weakening of 

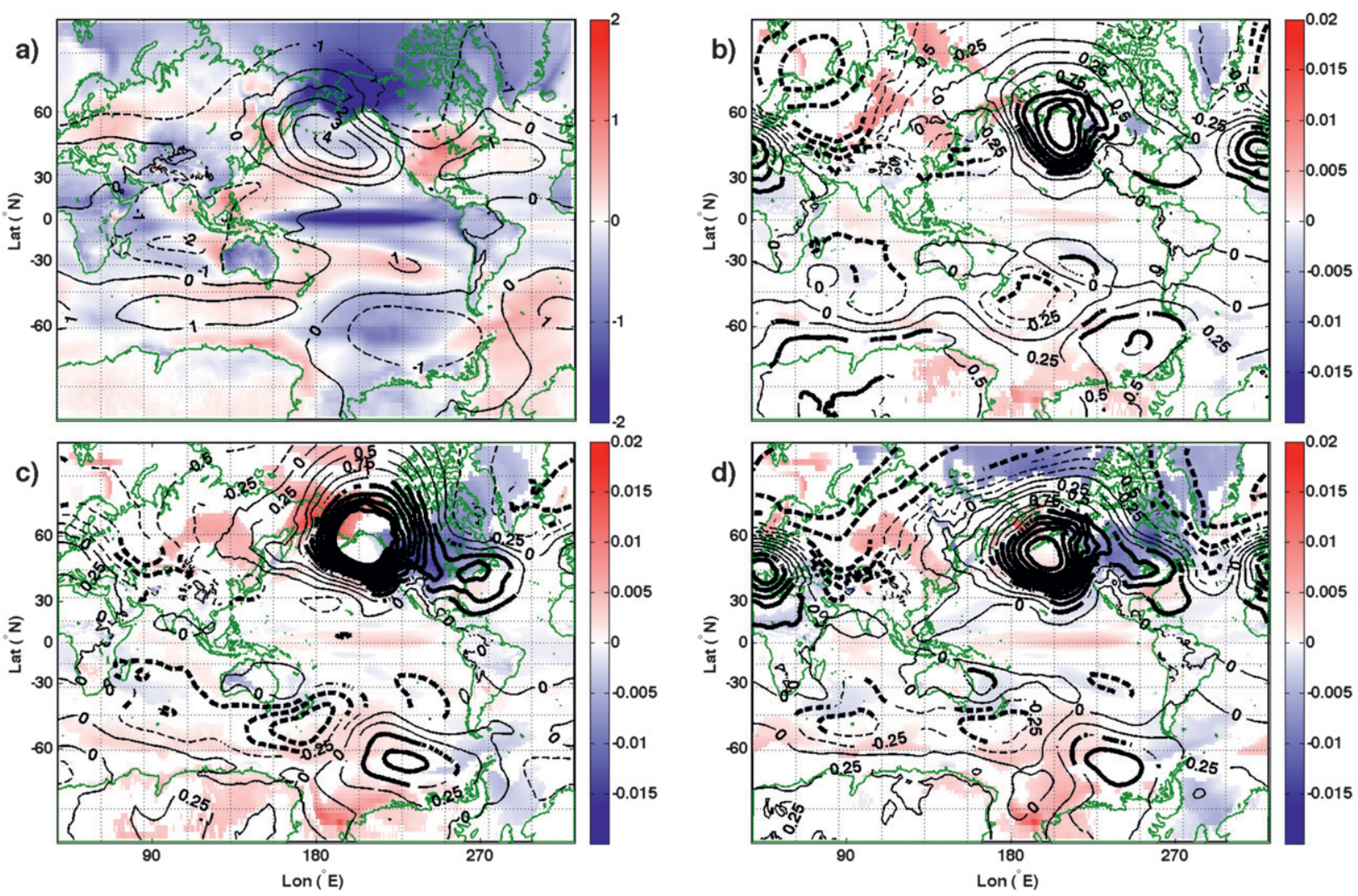

FIG. 6. As in Fig. 5, but for La Niña DJF.

the overall Australasian El Niño teleconnection, which could have implications for modeled ENSO-related drought and flooding in the region.

Another change seen during El Niño DJF appears similar to those documented in Meehl et al. (2007) and Meehl and Teng (2007): the North American teleconnection pattern shifts to the north and east with $\mathrm{CO}_{2}$. This is evidenced by the negative SLP anomalies over the northern United States and Canada and the positive SLP anomalies north of Hawaii near the southern edge of the Aleutian low in the twentieth-century El Niño DJF (Fig. 5a). Meehl and Teng (2007) attributed such shifts to an anomalous upper-tropospheric wave-5 pattern, related to a shift in the midlatitude mean circulation. The SAT and SLP anomalies in Fig. 5 are certainly consistent with such a hypothesis, but a more thorough analysis is left for future investigations.

During El Niño JJA, very few of the SLP differences observed are statistically significant (Fig. 7). There is a weakening of the high pressure anomaly in the Southern Hemisphere off the coast of Antarctica, with an accompanying positive SLP anomaly just to the north (near $50^{\circ} \mathrm{S}$ ); this may represent a southeastward shift of the overall teleconnection pattern in this region. During La Niña JJA, a similar pattern of opposite sign emerges, with positive SLP anomalies off the Antarctic coast and negative anomalies in the Southern Hemisphere extratropics. Anomalies near Antarctica are likely associated with changes to sea ice cover (Deser et al. 2012). Notably, there does not appear to be a monotonic trend between RCP ensembles in either El Niño or La Niña JJA teleconnection patterns; the Southern Hemisphere changes are much larger in RCP2.6 than the higher- $\mathrm{CO}_{2}$ ensembles. This may be related to the much faster radiative forcing stabilization in RCP2.6 (Moss et al. 2010).

In general, the larger responses seen in the SLP and air temperature diagnostics of Figs. 5-8, in comparison with the oceanic diagnostics examined in previous sections, are consistent with the faster response time of the atmosphere to a change in radiative forcing. It should be noted that the high pressure anomalies near the Aleutian Islands in La Niña DJF are substantial-up to $50 \%$ of the anomaly seen in the twentieth-century ensemble (Fig. 6a). Thus it is possible for a significant shift in ENSO teleconnections to take place in the atmospheric circulation well before the slower ocean circulation (and therefore tropical variability) has had time to stabilize. Future work on projections of atmospheric ENSO teleconnections and associated climate impacts is highly recommended. 

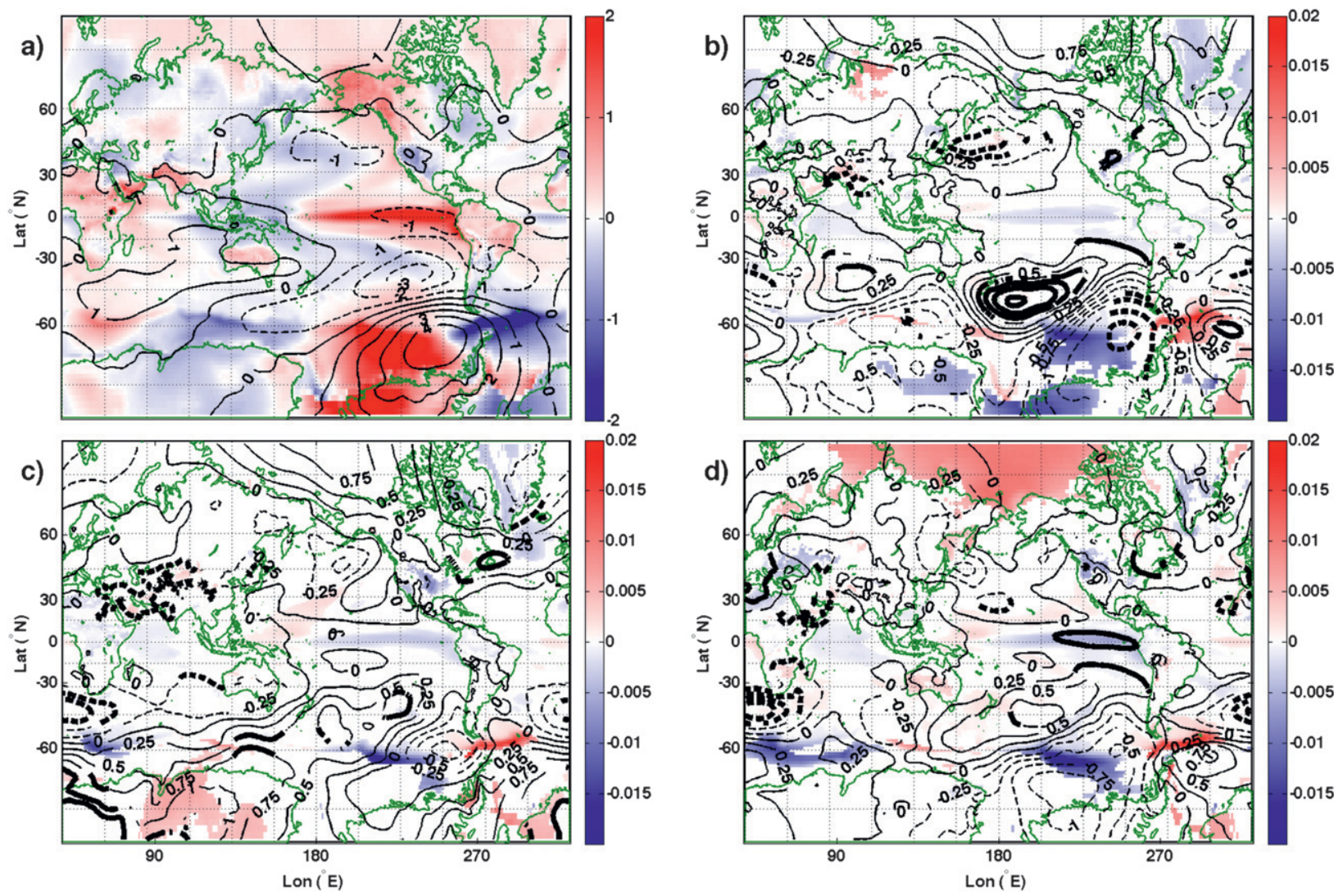

FIG. 7. As in Fig. 5, but for El Niño JJA.

Oceanic modes of variability were examined as well, to assess the validity of the slow response time hypothesis. And indeed, a lack of significant changes is seen; the two leading modes of thermocline variability (not shown) were computed following the approach of Capotondi et al. (2006). These modes show the "recharge oscillator" signals described by those authors, but no substantial change in either the pattern of variability of the percentage of variance explained was seen with $\mathrm{CO}_{2}$. Spectra of the principal components were statistically identical, and only minor qualitative changes to the spatial pattern were observed; this leads to the conclusion that the lack of significance in the ENSO amplitude signal applies to modes of thermocline variability as well. It is therefore difficult to conclude on the basis of these simulations that climate change will lead to any statistically significant alterations in oceanic modes of ENSO variability.

\section{Discussion}

The results of this study are interesting in the context of ongoing work on CMIP5, since they clearly demonstrate that the oceanic dynamics relevant for ENSO do not stabilize on centennial time scales in the CCSM4; even when changes to ENSO amplitude are expected to eventually become significant, more than a century of observations after the external forcing has stabilized may be necessary for that change to manifest itself. The exact length of observations necessary for robust ENSO statistics is likely sensitive to the magnitude of the extratropical trends, which in turn will depend on the degree of imposed external forcing. For example, ENSO in the RCP2.6 scenario likely stabilizes more quickly after 2100 than does the RCP8.5, since by then the radiative forcing in RCP2.6 has already stabilized while it continues to ramp up in RCP8.5. Changes to ENSO may be felt more or less quickly depending on the details of future $\mathrm{CO}_{2}$ emissions but are always delayed in arriving at the tropics via the wave and advective pathways (Boccaletti 2005).

This result has been obtained using only a single model, of course, and should be confirmed using other CMIP-class models. If this behavior is found to be a robust feature of GCMs, it has important implications for understanding ENSO dynamics and other questions such as assessing the frequency of event types. For example, even if "Modoki"-type events do become more frequent 

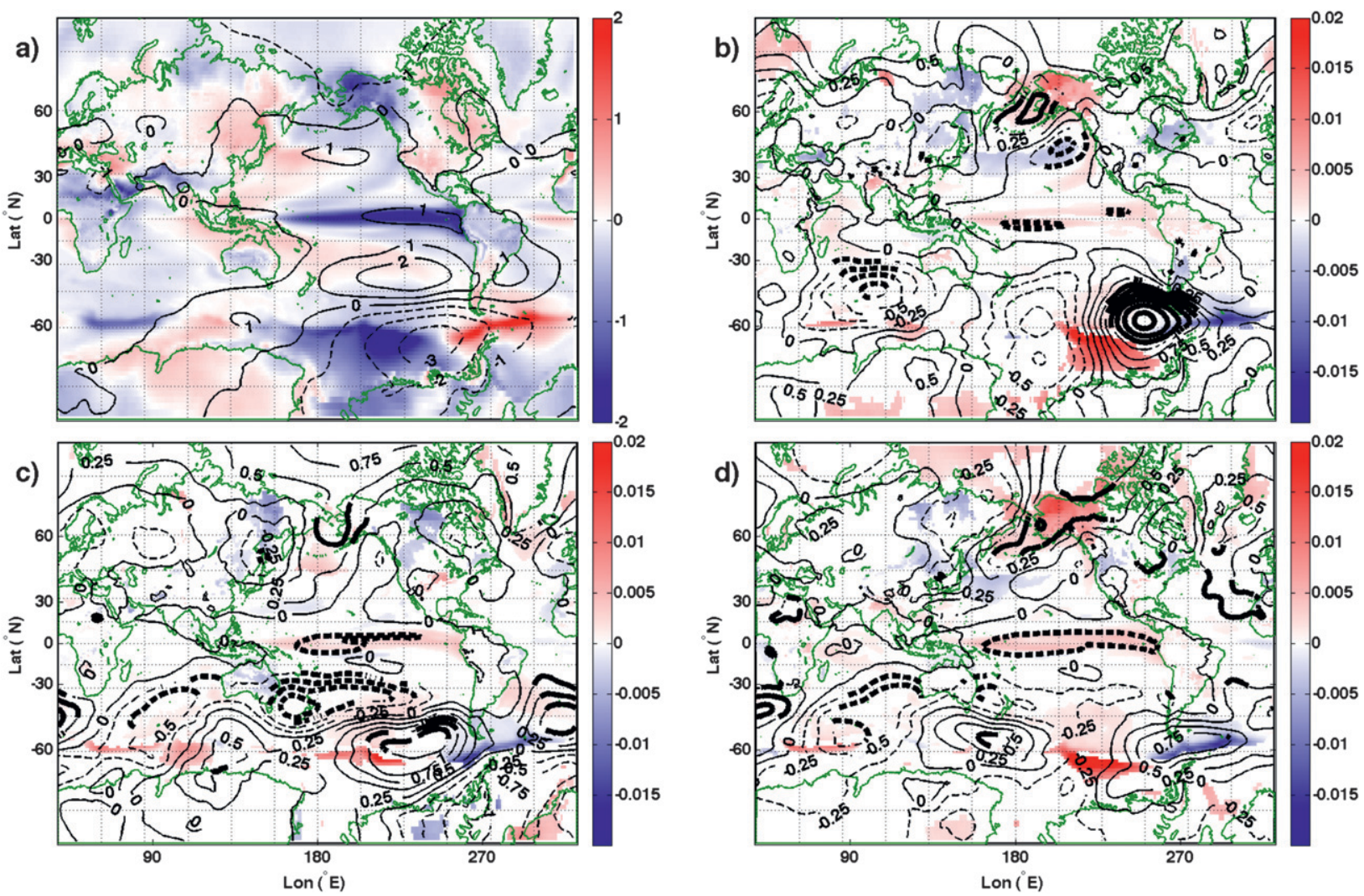

FIG. 8. As in Fig. 5, but for La Niña JJA.

in future climates (Yeh et al. 2009), based on these results one would not expect to detect such a change for several centuries.

It is also important to note that the equilibrated response does not provide the answer most relevant to society; for impacts studies, what matters is not the ENSO response in an idealized stable climate, but the change in long-term ENSO statistics under changing $\mathrm{CO}_{2}$ forcing. It is entirely possible that the observed slight ENSO amplitude weakening in the RCPs will become significant if $\mathrm{CO}_{2}$ continues to increase for long enough; however, all we currently know is that 100 years of observing the system is not enough to provide an answer. The ENSO response of extremely long ramp-up simulations is another interesting avenue of investigation.

Figures 5-8 have demonstrated that the fast atmospheric response time allows ENSO teleconnections to change before the oceanic statistics have stabilized (tropical ENSO variability has adjusted). This means that the possibility of significant changes to societally relevant quantities such as rainfall (Cayan et al. 2010; Mason and Goddard 2001) in the next few decades cannot be excluded on the basis of these results. This is especially relevant when considering factors such as land-use changes in the RCPs. The assumptions regarding projected future agricultural activity are dramatically different between RCPs (van Vuuren et al. 2007; Clarke et al. 2007; Fujino et al. 2006; Riahi et al. 2007), and this has the potential to affect ENSO-relevant atmospheric circulation patterns. Although not considered in this study, a more detailed examination of the impact of land-use changes on ENSO in the CCSM4 would be a valuable next step.

The rapid response of atmospheric teleconnections to $\mathrm{CO}_{2}$ also has important implications for paleoclimatic studies: most investigations of paleo-ENSO explicitly or implicitly assume that teleconnections remain stationary (Mann et al. 2008, 2009; Molnar and Cane 2002, 2007). But these results clearly show that the oceanic and atmospheric responses change on vastly different time scales. In other words, atmospheric teleconnections should not be viewed as robust indicators of changes to past ENSO variability.

Future work will assess the details of the equilibrium ENSO response to $\mathrm{CO}_{2}$ increases in the CCSM4. The stabilized runs in this study only cover a small portion of the potential range in $\mathrm{CO}_{2}$ forcing due to anthropogenic climate change; does the system continue to respond in the same way at higher and higher $\mathrm{CO}_{2}$ ? There is some evidence that ENSO behavior may radically change at very high (but plausible) $\mathrm{CO}_{2}$ concentrations (Cherchi et al. 2008). Once the extension runs for the other forcing 
pathways become available, it will become possible to perform a much more detailed diagnosis of the behavior of ENSO in response to $\mathrm{CO}_{2}$.

The implications of this study for intermodel comparison are also important. In the context of the long dynamical time scales observed in the CCSM4, the disagreements between model ENSO projections seen by Collins et al. (2010) should be expected. If multiple centuries at stable $\mathrm{CO}_{2}$ are required to observe significant changes to ENSO, then it should come as no surprise that looking at much shorter integrations leads to conflicting results. Additionally, the differences in ENSO amplitude change between the stable CCSM4 simulations in this study and the equilibrated runs of Stevenson et al. (2011, manuscript submitted to J. Climate) prove that even within a given model family, small changes to physics can lead to diametrically opposing results. Are the intermodel differences seen in the Collins et al. (2010) due to the short simulation length, or are there real differences in ENSO climate sensitivity? Answering this question will require dedicated millennial-scale simulations with stable mean climates using multiple models, which is recommended for future investigations.

\section{Conclusions}

This study has provided a first look at the response of ENSO to climate change in the CCSM4. Several different metrics show that the change in ENSO amplitude from the twentieth-century value is statistically insignificant between most RCP ensembles. The overall 2-7-yr Niño-3 variance is indistinguishable between most ensembles, although a K-S test shows that the PDFs of Niño-3 SST and of scale-averaged wavelet power values do alter significantly within and between ensembles. Application of the WPA tools of Stevenson et al. (2010) then shows that despite the change in PDF, these shifts are consistent with what one might expect because of natural variability alone.

Notably, the situation may be much different in stabilized climates - the shrinking of the $90 \%$ error bar on Niño-3.4 variance in the stabilized CCSM4 1850 control suggests that ENSO changes could become significant on multicentury time scales, although averaging more than 200 years of each simulation will likely be required to observe such significance (i.e., Wittenberg 2009; Stevenson et al. 2010). Note that the combined length of the RCP ensembles $(5 \times 95 \mathrm{yr}=475 \mathrm{yr}$ total $)$ is much longer than the extension run, yet no signal is seen; from a societal perspective, these results indicate that an individual ENSO event, or even a few decades of anomalous ENSO events such as the period from the 1970s to the present, cannot be attributed to forcing due to present $\mathrm{CO}_{2}$ emissions. Instead, they can only be attributed to a combination of changes in past forcing and natural variability. This also indicates that the true range in model ENSO sensitivity to climate change remains an unknown and must be determined using multicentury control simulations at varying $\mathrm{CO}_{2}$ concentrations.

Mean-state changes in response to $\mathrm{CO}_{2}$ increases in CCSM4 are generally similar to those seen in CCSM3. The eastern Pacific SST warms along the equator, the equatorial trade winds weaken, the hydrological cycle becomes more intense, and ocean stratification increases with $\mathrm{CO}_{2}$. Thermocline anomalies in the extratropics persist throughout the course of the twentieth-twentyfirst centuries, with the trend becoming stronger in the higher- $\mathrm{CO}_{2}$ ensembles. The time scales for dynamical adjustment expected in the system are on the order of decades, meaning that the tropics may not be fully "spun up" in response to $\mathrm{CO}_{2}$ changes by the end of the twentyfirst century. In the RCP4.5 extension simulation the trends are much smaller; perhaps ENSO changes will become detectable after $\mathrm{CO}_{2}$ stabilizes.

Changes to ENSO atmospheric teleconnections do occur between ensembles, although the magnitude of changes to tropical surface air temperatures is very small. The wide variety of possible teleconnections makes a complete analysis beyond the scope of this paper, but surface air temperature and sea level pressure were examined during both El Niño and La Niña in DJF and JJA. Interensemble changes to the El Niño DJF SLP anomalies are consistent with previous results (Meehl et al. 2007; Meehl and Teng 2007); a northeastward shift in the North American teleconnection pattern occurs with increased $\mathrm{CO}_{2}$, possibly indicating a change in the mean upper-air circulation. During La Niña, the DJF SLP anomaly south of Alaska increases dramatically with $\mathrm{CO}_{2}$, strengthening the blocking high over the Aleutians and creating much colder surface temperatures in Canada and the northern United States.

In the Southern Hemisphere, changes during DJF take place over Australia, which tend to oppose the prevailing ENSO teleconnections. El Niño years show a positive SLP anomaly south of Tasmania, with a negative anomaly over mainland Australia and Indonesia. During La Niña, the opposite is true; this seems to indicate that climate change will lead to weaker ENSO-related impacts in the region during DJF, at least in the CCSM4. Changes during JJA are less conclusive and changes with $\mathrm{CO}_{2}$ are generally nonmonotonic-Southern Hemisphere SLP changes appear stronger in RCP2.6 than the higher- $\mathrm{CO}_{2}$ ensembles. However, the presence of statistically significant SAT and SLP changes demonstrates that it is possible for atmospheric teleconnections to respond to climate 
change in the absence of statistically robust changes to oceanic-tropical variability.

The contrast between the (lack of) oceanic response and the stronger atmospheric response is quite interesting. When modes of oceanic variability were examined, no consistent pattern of changes was observed with $\mathrm{CO}_{2}$. The logical conclusion is that the diagnosis of a robust oceanic ENSO response to climate change in the CCSM4 is simply not possible until long after the $\mathrm{CO}_{2}$ forcing has stabilized, even using extremely large ensembles to average over natural variability. However, changes to the impacts of the oscillation may be felt much sooner, owing to the much shorter atmospheric response time scale. Investigations of ENSO with other coupled models in the twenty-first century and in stabilized climates should prove extremely valuable as a confirmation of these results.

Acknowledgments. This research used computing resources of the Climate Simulation Laboratory at the National Center for Atmospheric Research (NCAR), which is sponsored by the National Science Foundation; the Oak Ridge Leadership Computing Facility, which is supported by the Office of Science of the U.S. Department of Energy under Contract DE-AC05-00OR22725; and the National Energy Research Scientific Computing Center, which is supported by the Office of Science of the U.S. Department of Energy under Contract DE-AC0205CH11231. We acknowledge Adrianne Middleton, Andy Mai, and Diane Feddema at NCAR who helped perform the model runs, as well as members of the Community Earth System Model (CESM) Software Engineering Group who also made important contributions. Portions of this study were supported by the Office of Science, Biological and Environmental Research, U.S. Department of Energy, Cooperative Agreement DEFC02-97ER62402, and the National Science Foundation. Support for SS was provided by NASA NNX09AO20H; BFK was supported by NSF FRG 0855010.

\section{REFERENCES}

Alexander, M. A., I. Bladé, M. Newman, J. R. Lanzante, N.-C. Lau, and J. D. Scott, 2002: The atmospheric bridge: The influence of ENSO teleconnections on air-sea interaction over the global oceans. J. Climate, 15, 2205-2231.

Battisti, D. S., and A. C. Hirst, 1989: Interannual variability in a tropical atmosphere ocean model: Influence of the basic state, ocean geometry, and nonlinearity. J. Atmos. Sci., 46, 1687-1712.

Blanke, B., and S. Raynaud, 1997: Kinematics of the Pacific Equatorial Undercurrent: An Eulerian and Lagrangian approach from GCM results. J. Phys. Oceanogr., 27, 1038-1053.

Boccaletti, G., 2005: Timescales and dynamics of the formation of a thermocline. Dyn. Atmos. Oceans, 39, 21-40.

— R. Pacanowski, S. Philander, and A. Fedorov, 2004: The thermal structure of the upper ocean. J. Phys. Oceanogr., 34, 888-902.
Bony, S., and J.-L. Dufresne, 2005: Marine boundary layer clouds at the heat of tropical cloud feedback uncertainties in climate models. Geophys. Res. Lett., 32, L20806, doi:10.1029/ 2005GL023851.

Cane, M. A., and E. Sarachik, 1979: Forced baroclinic ocean motion. III: An enclosed ocean. J. Mar. Res., 37, 355-398.

—, A. C. Clement, A. Kaplan, Y. Kushnir, D. Pzdnyakov, R. Seager, S. E. Zebiak, and R. Murtugudde, 1997: Twentiethcentury sea surface temperature trends. Science, 275, 957-960.

Capotondi, A., A. Wittenberg, and S. Masina, 2006: Spatial and temporal structure of tropical Pacific interannual variability in 20th century coupled simulations. Ocean Modell., 15, 274-298.

Cayan, D. R., K. T. Redmond, and L. G. Riddle, 2010: ENSO and hydrologic extremes in the western United States. J. Climate, 12, 2881-2893

Cherchi, A., S. Masina, and A. Navarra, 2008: Impact of extreme $\mathrm{CO}_{2}$ levels on tropical climate: A CGCM study. Climate Dyn., 31, 743-758.

Clarke, L., J. Edmonds, H. Jacoby, H. Pitcher, J. Reilly, and R. Richels, 2007: Scenarios of greenhouse gas emissions and atmospheric concentrations. U.S. Climate Change Science Program and the Subcommittee on Global Change Research Sub-Rep. 2.1A of Synthesis and Assessment Product 2.1, Department of Energy, Office of Biological and Environmental Research, 154 pp.

Collins, M., and Coauthors, 2010: The impact of global warming on the tropical Pacific Ocean and El Niño. Nat. Geosci., 3, 391397, doi:10.1038/NGEO868.

Dai, A., K. E. Trenberth, and T. R. Karl, 1998: Global variations in droughts and wet spells: 1900-1995. Geophys. Res. Lett., 25, 3367-3370.

Danabasoglu, G., and J. Marshall, 2007: Effects of vertical variations of thickness diffusivity in an ocean general circulation model. Ocean Modell., 18, 122-141.

Deser, C., A. Capotondi, R. Saravanan, and A. Phillips, 2006: Tropical Pacific and Atlantic climate variability in CCSM3. J. Climate, 19, 2451-2481.

, and Coauthors, 2012: ENSO and Pacific decadal variability in Community Climate System Model version 4. J. Climate, in press.

Dettinger, M. D., D. R. Cayan, G. J. McCabe, and J. M. Marengo, 2000: Multiscale stream-flow variability associated with El Niño/Southern Oscillation. El Niño and the Southern Oscillation: Multiscale Variability and Global and Regional Impacts, H. F. Diaz and V. Markgraf, Eds., Cambridge University Press, 113-147.

Diaz, H. F., M. P. Hoerling, and J. K. Eischeid, 2001: ENSO variability, teleconnections and climate change. Int. J. Climatol., 21, 1845-1862.

Fedorov, A. V., and S. G. Philander, 2001: A stability analysis of tropical ocean-atmosphere interactions: Bridging measurements and theory for El Niño. J. Climate, 14, 3086-3101.

Fox-Kemper, B., and Coauthors, 2011: Parameterization of mixed layer eddies. III: Implementation and impact in global ocean climate simulations. Ocean Modell., 39, 61-78.

Fujino, J., R. Nair, M. Kainuma, T. Masui, and M. Matsuoka, 2006: Multigas mitigation analysis on stabilization scenarios using AIM global model. Energy J., 3, 343-354.

Gastineau, G., L. Li, and H. Le Trent, 2009: The Hadley and Walker circulation changes in global warming conditions described by idealized atmospheric simulations. J. Climate, 22, 3993-4013.

Gebbie, G., I. Eisenman, A. Wittenberg, and E. Tziperman, 2007: Modulation of westerly wind bursts by sea surface temperature: 
A semi-stochastic feedback for ENSO. J. Atmos. Sci., 64, 3281-3295.

Gent, P. R., and Coauthors, 2011: The Community Climate System Model version 4. J. Climate, 24, 4973-4991.

Gu, D., and S. Philander, 1997: Interdecadal climate fluctuations that depend on exchanges between the tropics and the extratropics. Science, 275, 805-807.

Guilyardi, E., 2006: El Niño-mean state-seasonal cycle interactions in a multi-model ensemble. Climate Dyn., 26, 329-348.

, A. Wittenberg, A. Fedorov, M. Collins, C. Wang, A. Capotondi, G. Jan van Oldenborgh, and T. Stockdale, 2009: Understanding El Niño in ocean-atmosphere general circulation models: Progress and challenges. Bull. Amer. Meteor. Soc., 90, 325340.

Held, I., and B. Soden, 2006: Robust responses of the hydrological cycle to global warming. J. Climate, 19, 5686-5699.

Jin, F.-F., 1997: A theory of interdecadal climate variability of the North Pacific Ocean-atmosphere system. J. Climate, 10, 1821-1835.

— W.-I. An, A. Timmermann, and J. Zhao, 2003: Strong El Niño events and nonlinear dynamical heating. Geophys. Res. Lett., 30, 1120, doi:10.1029/2002GL016356.

_ S. T. Kim, and L. Bejarano, 2006: A coupled-stability index for ENSO. Geophys. Res. Lett., 33, L33708, doi:10.1029/ 2006GL027221.

Jochum, M., 2009: Impact of latitudinal variations in vertical diffusivity on climate simulations. J. Geophys. Res., 114, C01010, doi:10.1029/2008JC005030.

—_, G. Danabasoglu, M. Holland, Y.-O. Kwon, and W. Large, 2008: Ocean viscosity and climate. J. Geophys. Res., 113, C06017, doi:10.1029/2007JC004515.

— B. Box-Kemper, P. Molnar, and C. Shields, 2009: Differences in the Indonesian seaway in a coupled climate model and their relevance to Pliocene climate and El Niño. Paleoceanography, 24, PA1212, doi:10.1029/2008PA001678.

_ S. Yeager, K. Lindsay, K. Moore, and R. Murtugudde, 2010: Quantification of the feedback between phytoplankton and ENSO in the Community Climate System Model. J. Climate, 23, 2916-2925.

Kao, H.-Y., and J.-Y. Yu, 2009: Contrasting eastern Pacific and central Pacific types of ENSO. J. Climate, 22, 615-632.

Kessler, W. S., 2006: The circulation of the eastern tropical Pacific: A review. Prog. Oceanogr., 69, 181-217, doi:10.1016/ j.pocean.2006.03.009.

Large, W. G., and G. Danabasoglu, 2006: Attribution and impacts of upper-ocean biases in CCSM3. J. Climate, 19, 2325-2346.

Lengaigne, M., and G. Vecchi, 2009: Contrasting the termination of moderate and extreme El Niño events in coupled general circulation models. Climate Dyn., 35, 299-313, doi:10.1007/ s00382-009-0562-3.

Lin, S.-J., 2004: A vertically Lagrangian finite-volume dynamical core for global models. Mon. Wea. Rev., 132, 2293-2307.

— Lagrangian transport schemes. Mon. Wea. Rev., 124, 20462070.

Liu, Z., and S. Philander, 1995: How different wind stress patterns affect the tropical-subtropical circulations of the upper ocean. J. Phys. Oceanogr., 25, 449-462.

- S. Vavrus, F. He, N. Wen, and Y. Zhong, 2005: Rethinking tropical ocean response to global warming: The enhanced equatorial warming. J. Climate, 18, 4684-4700.

Mann, M. E., Z. Zhang, M. K. Hughes, R. S. Bradley, S. K. Miller, S. Rutherford, and F. Ni, 2008: Proxy-based reconstructions of hemispheric and global surface temperature variations over the past two millennia. Proc. Natl. Acad. Sci. USA, 105, 13 253-13 257.

— gins of the little ice age and medieval climate anomaly. Science, 326, 1256-1260.

Mason, S. J., and L. Goddard, 2001: Probabilistic anomalies associated with ENSO. Bull. Amer. Meteor. Soc., 82, 619-638.

McCabe, G. J., and M. D. Dettinger, 1999: Decadal variations in the strength of ENSO teleconnections with precipitation in the western United States. Int. J. Climatol., 19, 8847-8850.

McPhaden, M. J., 1999: Genesis and evolution of the 1997/98 El Niño. Science, 283, 950-954.

— and D. Zhang, 2002: Slowdown of the meridional overturning circulation in the upper Pacific Ocean. Nature, 415, 603-608.

Meehl, G. A., and H. Teng, 2007: Multi-model changes in El Niño teleconnections over North America in a future warmer climate. Climate Dyn., 29, 779-790, doi:10.1007/s00382-007-0268-3.

$\ldots, \ldots$, and G. Branstator, 2006: Future changes of El Niño in two global coupled climate models. Climate Dyn., 26, 549-566, doi:10.1007/s00382-005-0098-0.

— C. Tebaldi, H. Teng, and T. C. Peterson, 2007: Current and future U.S. weather extremes and El Niño. Geophys. Res. Lett., 34, L20704, doi:10.1029/2007GL031027.

Merryfield, W. J., 2006: Changes to ENSO under $\mathrm{CO}_{2}$ doubling in a multimodel ensemble. J. Climate, 19, 4009-4027.

Molnar, P., and M. A. Cane, 2002: El Niño's tropical climate and teleconnections as a blueprint for pre-Ice Age climates. $\mathrm{Pa}$ leoceanography, 17, doi:10.1029/2001PA000663.

— global climate: Which El Niño? Geosphere, 3, 337-365, doi:10.1130/GES00103.1.

Montgomery, D., and G. Runger, 2007: Applied Statistics and Probability for Engineers. John Wiley \& Sons, 768 pp.

Moss, R., and Coauthors, 2010: The next generation of scenarios for climate change research and assessment. Nature, 463, 747-756.

Neale, R. B., and Coauthors, 2011: Description of the NCAR Community Atmosphere Model (CAM4). National Center for Atmospheric Research Tech. Rep. NCAR/TN-485+STR, 212 pp.

Neelin, J. D., and Coauthors, 1992: Tropical air-sea interaction in general circulation models. Climate Dyn., 7, 73-104.

Okumura, Y., and C. Deser, 2010: Asymmetry in the duration of El Niño and La Niña. J. Climate, 23, 5826-5843.

Philip, S., and G. van Oldenborgh, 2006: Shifts in ENSO coupling processes under global warming. Geophys. Res. Lett., 33, L11704, doi:10.1029/2006GL026196.

— versus observations. Climate Dyn., 34, 1073-1091.

Power, S., T. Casey, C. Folland, A. Colman, and V. Mehta, 1999: Interdecadal modulation of the impact of ENSO on Australia. Climate Dyn., 15, 319-324.

—, M. Haylock, R. Colman, and X. Wang, 2006: The predictability of interdecadal changes in ENSO activity and ENSO teleconnections. J. Climate, 19, 4755-4771.

Rajagopalan, B., K. Nowak, J. Prairie, M. Hoerling, B. Harding, J. Barsugli, A. Ray, and B. Udall, 2009: Water supply risk on the Colorado River: Can management mitigate? Water Resour. Res., 45, W08201, doi:10.1029/2008WR007652.

Riahi, K., A. Grubler, and N. Nakicenovic, 2007: Scenarios of longterm socio-economic and environmental development under climate stabilization. Technol. Forecast. Soc. Change, 74, 887935. 
Richter, J. H., and P. J. Rasch, 2008: Effects of convective momentum transport on the atmospheric circulation in the Community Atmosphere Model. J. Climate, 21, 1487-1499.

Seager, R., 2007: The turn of the century North American drought: Global context, dynamics, and past analogs. J. Climate, 20, $5527-5552$.

Stevenson, S., B. Fox-Kemper, M. Jochum, B. Rajagopalan, and S. Yeager, 2010: Model ENSO validation using wavelet probability analysis. J. Climate, 23, 5540-5547.

Suarez, M. J., and P. S. Schopf, 1988: A delayed action oscillator for ENSO. J. Atmos. Sci., 45, 3283-3287.

Subramanian, A., M. Jochum, A. Miller, R. Murtugudde, R. Neale, and D. Waliser, 2011: The Madden-Julian oscillation in CCSM4. J. Climate, 24, 6261-6282.

Sun, D.-Z., 2003: A possible effect of an increase in the warm-pool SST on the magnitude of El Niño warming. J. Climate, 16, 185-205.

Thompson, C. J., and D. S. Battisti, 2001: A linear stochastic dynamical model of ENSO. Part II: Analysis. J. Climate, 14, 445-466.

Timmermann, A., J. Oberhuber, A. Bacher, M. Esch, M. Latif, and E. Roeckner, 1999: Increased El Niño frequency in a climate model forced by future greenhouse warming. Nature, 398, 694-697.

Torrence, C., and G. Compo, 1998: A practical guide to wavelet analysis. Bull. Amer. Meteor. Soc., 79, 61-78.

Trenberth, K., and J. W. Hurrell, 1994: Decadal atmosphere-ocean variations in the Pacific. Climate Dyn., 9, 303-319.

van Vuuren, D., M. den Elzen, P. Lucas, B. Eickhout, B. Strengers, B. van Ruijven, S. Wonink, and R. van Houdt, 2007: Stabilizing greenhouse gas concentrations at low levels: An assessment of reduction strategies and costs. Climatic Change, 81, 119-159.
Vavrus, S., and D. Waliser, 2008: An improved parameterization for simulating Arctic cloud amount in the CCSM3 climate model. J. Climate, 21, 5673-5687.

Vecchi, G., and B. Soden, 2007: Global warming and the weakening of the tropical circulation. J. Climate, 20, 4316-4340.

—, and A. Wittenberg, 2010: El Niño and our future climate: Where do we stand? Wiley Interdiscip. Rev.: Climate Change, 1, 260-270

Wang, B., and S.-I. An, 2001: Why the properties of El Niño changed during the late 1970s. Geophys. Res. Lett., 28, 3709-3712.

Wang, C., and J. Picaut, 2004: Understanding ENSO physics-A review. Earth's Climate: The Ocean-Atmosphere Interaction, Geophys. Monogr., Vol. 405, Amer. Geophys. Union, 21-48.

Weisberg, R. H., and C. H. Wang, 1997: A western Pacific oscillator paradigm for the El Niño-Southern Oscillation. Geophys. Res. Lett., 24, 779-782.

Wittenberg, A. T., 2009: Are historical records sufficient to constrain ENSO simulations? Geophys. Res. Lett., 36, L12702, doi:10.1029/2009GL038710.

Xie, S.-P., C. Deser, G. Vecchi, J. Ma, H. Teng, and A. Wittenberg, 2010: Global warming pattern formation: Sea surface temperature and rainfall. J. Climate, 23, 966-986.

Yeh, S.-W., Y.-G. Park, and B. P. Kirtman, 2006: ENSO amplitude changes in climate change commitment to atmospheric $\mathrm{CO}_{2}$ doubling. Geophys. Res. Lett., 33, L13711, doi:10.1029/ 2005GL025653.

, J.-S. Kug, B. Dewitte, M.-H. Kwon, B. P. Kirtman, and F.-F. Jin, 2009: El Niño in a changing climate. Nature, 461, 511-514, doi:10.1038/nature08316.

Zhang, L., P. Chang, and L. Ji, 2009: Linking the Pacific Meridional Mode to ENSO: Coupled model analysis. J. Climate, 22, 34883505 